\title{
Towards a Better Understanding of Open Source Hardware Design Reuse in Company-Community Collaboration
}

\author{
Amer Ezoji $^{1(\otimes)}$, Romain Pinquie ${ }^{2}$, and Jean François Boujut ${ }^{2}$ \\ ${ }^{1}$ Univ. Grenoble Alpes, CNRS, Grenoble INP (Institute of Engineering Univ. Grenoble Alpes), \\ G-SCOP, 38000 Grenoble, France \\ amer.ezoji@grenoble-inp.fr \\ 2 Univ. Grenoble Alpes, CNRS, Grenoble INP, G-SCOP, 38000 Grenoble, France
}

\begin{abstract}
The open-source-software movement that emerged in the late 90s has recently extended to hardware. In this paper, we try to better understand how the reuse of design solutions facilitates company-community collaboration. On the one hand, based on existing research studies, we analyze three fundamental questions - 1) who wants to reuse a design? 2) Why do they want to reuse a design?, and 3) How do they reuse a design? - from a company perspective and a community perspective. On the other hand, we identified that companies and communities must create a common understanding of the design problems and solution and they could benefit in reusing design artifact to speed up the development time and improve the quality and transferability of the results. However, this research shows that companies and communities don't use the same type of tools and methods to reuse design knowledge which may cause some problems for collaboration [2].
\end{abstract}

Keywords: Open design · Open source hardware $\cdot$ Design reuse $\cdot$ Design collaboration

\section{Introduction}

Open source refers to a product development movement where the source of the product (software, hardware, or hybrid) is publicly accessible so as to create derived works. The open source movement has its origin in the software community. Open source software is a term for software published under licenses that do not give any private intellectual property rights to the developers. The source code is publicly and freely accessible so that anyone can reuse it with or without prior modification [3]. The transfer of open source principles from software development to the world of physical objects gave birth to the phenomenon of open source hardware (OSH). OSH is piece of hardware whose design is made publicly available so that anyone can study, modify, distribute, make, and sell the design or hardware [5]. OSH falls in the category of open source innovation. The development of OSH relies on open design. Open design is "the openness of all accompanying documents in a product development process, with the aim of collaborative development of tangible objects" [4]. One major benefit of open design is 
to provide designers with the ability to reuse solutions in an open collaboration ${ }^{1}$. Design reuse which is an activity that consists in using an existing design, in whole or in part, to fulfill a new set of requirements is a critical issue for the development of OSH. So, the goal of this research is to identify the main issues of design reuse practices in the company and community and provide significant conditions to facilitate design reuse in company-community collaboration.

\section{Design Reuse in Company and Community}

In this section, we review the current methods and technologies supporting design reuse in two contexts. First, we consider the work of design reuse in business. Second, we focus on the design reuse in $\mathrm{OSH}$ communities.

\subsection{Design Reuse in Companies}

To better understand the existing design reuse practices in a company, we analyze "who" reuse a design artifact, "why" and "how" do they reuse it.

\section{- Who in a company want to reuse the design?}

In a company the main stakeholder for design reuse is a design engineer. Design engineers use up to $70 \%$ of paste design knowledge to solve new design problems [16] while minimizing resources and efforts.

\section{- Why a company reuses design?}

Given the competitive pressures in business, design reuse enables companies to reduce costs and time-to-market while maximizing customer satisfaction [16] by finishing the design task in a shorter time, reducing of delivery times, shortening the testing phase and improving the quality $[13,15]$.

\section{- How does a company facilitate the reuse of design?}

Companies use a mix of techniques to facilitate design reuse. The first technique aims at using a design rationale to capture the reasons and arguments leading to a design decision $[7,11]$. The second technique consists in organizing the design data and using data structures such as ontologies [14]. The third technique corresponds to careful management of data using information systems such as PDM/PLM software [9]. When such database-based information systems fail to retrieve existing designs, information retrieval techniques such as search engines can facilitate design reuse. In computer-aided design environment, the use of data exchange formats, the storage of models in wellstructured libraries, and the capitalization with templates facilitate design reuse. Design methods, especially modular product architecture approach may, also foster design reuse [12].

${ }^{1}$ Open collaboration is "any system of innovation or production that relies on goal-oriented yet loosely coordinated participants who interact to create a product (or service) of economic value, which they make available to contributors and noncontributory alike" (Levine, S. 2014). 


\subsection{Design Reuse in Communities}

Design reuse in $\mathrm{OSH}$ communities is hardly documented. Thus, to better understand the characteristics of reuse in open design, we rely on:

\section{- Who in a community want to reuse the design?}

In the previous project "OPEN - Methods and tools for community-based product development", a qualitative research approach aimed at deriving personas. Personas are ideal types that represent a category of user. A persona is described in all its dimensions (i.e. social, family, occupation, etc.) and can be integrated in user stories or scenarios. The qualitative analysis of 23 interviews led to 5 personas: 1) The participant in open source development [5] (OSD) projects (A) 2) The inventive creator (B) 3) The entrepreneur and open source process [6] (OSP) founder (C) 4) Community manager \& Visionary (D) 5) The maker \& Geek (E)

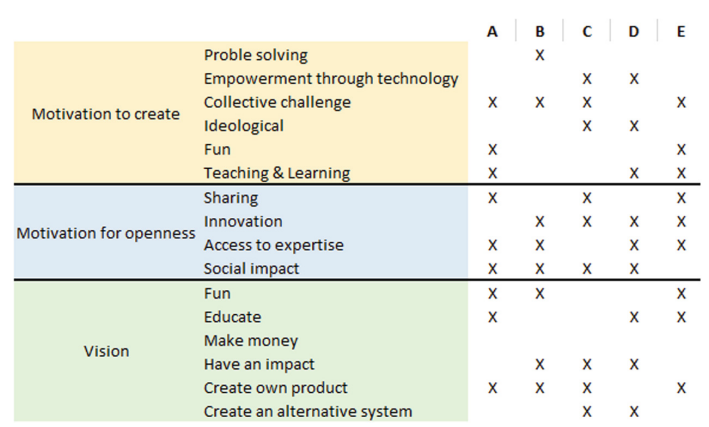

Fig. 1. Qualitative analysis of 23 interviews in community for design reuse

Among the 5 personas, the Maker \& Geek, the participant in OSD projects and potentially the inventive creator are the main stakeholders for design reuse. However, these personas may have potentially different needs in terms of reuse and we need to characterize them.

\section{- Why a community should reuse designs?}

A member who is involved in a community-based and open source product development process shares some fundamental motivations with a company since, when reusing a design, he is willing to reduce the design time and costs, to cover a lack of expertise, or to avoid design errors, that is, choices that make certain designs "not allowed" or inappropriate for their intended use. However, open design breathes life into product design since individual objectives - e.g. personal development and process learning [2], fame, or political and ethical actions - drive community members [7]. In the previous project OPEN, the analysis of the 23 interviews concluded that the motivations for being active in a community-based $\mathrm{OSH}$ are development project were:

- CAT 1: problem solving, empowerment through technology, collective challenge, ideological, fun, teaching and learning. 
- CAT 2: sharing, innovation, access to expertise, social impact.

- CAT 3: have fun, educate, make money, have in impact, create our own product, and create an alternative system.

\section{- How does a community facilitate the reuse of design?}

The strong influence of ICT on OSH development has brought new mechanisms that facilitate design reuse. For instance, web-based repositories such as Wikifactory, Hac kster or Hackaday that support the development of OSH provide anyone with a free and open access to the design artifacts protected by open source designs. Such platforms also integrate some basic but essential capabilities supporting the three functional spaces of collaboration [6]:

- Communication with social features and online documentation (stories, collections, activity and news feeds, forums, chats, wiki, etc.),

- Cooperation with configuration management features (concurrent text editing, issue tracking, version control, etc.)

- Coordination with project management capabilities (markdown task lists, notifications, milestones, task allocation through workflows, etc.)

The recent adoption of linked data (semantic web) also facilitates the reuse of designs because the retrieval and navigation across existing related OSH projects on the Web becomes easier than a few years ago. For instance, the Open Source Hardware Observatory is a semantic search engine that crawls the web and makes its content searchable. However, the reuse of the design artifacts required to recreate or modify OSH is often challenging because most design knowledge (assumptions, rules, choices...) remains tacit knowledge (e.g. commonsense) or unrecognized knowledge (e.g. expertise and skill). When one accesses the repository of an open source project, the quantity of recognized and codified knowledge in models is relatively limited. Indeed, in most cases, the repository only includes a snapshot of the solution at a given time, that is, a set of models, codes, [...], and documents without the underlying design rationales that conducted to the actual solution. The lack of organization and traceability in the design process of OSH makes difficult the reuse of models and the collaboration between companies and communities.

\section{Design Reuse in Company-Community Collaboration}

The necessary conditions for a collaborative design are: (1) have a common vocabulary/understanding about the design content and design process (communication), (2) have a common goal/aim, (3) use compatible technologies/tools, and (4) be engage in knowledge creation by sharing of design knowledge and integration [1, 8]. In the following sub-sections, we identify the enabling design reuse in company-community collaboration according to the key conditions for collaborative design and comparison between Sects. 2.1 and 2.2. 


\section{- Who in company-community collaboration could reuse design?}

Company-community collaboration requires stakeholders to share a common understanding of the design and shall consequently an engineering background. Therefore, the actors who are prone to reuse a design are potentially design engineers from company side and makers/geek from community side.

\section{- Why a company-community member could reuses design?}

Companies and communities could reuse design artifacts because they share common goals. Common goals include, but are not limited to, the learning of new skills - either to improve the current situation or to compensate for a lack of expertise -, the motivation to avoid design errors and rework iterations, the need for boosting creativity, and - for some makers - the willingness to develop new business opportunities by limiting costs, time-to-market, and risks.

\section{- How a company-community collaboration member could facilitate the reuse of design?}

Design reuse for the development of OSH in company-community collaboration is neither limited by the technical skills of collaborators nor by the lack of shared goals. Unfortunately, from a technological point of view, companies and communities do not use the same type of practices and software to capture and reuse design knowledge. Although both actors use ICT to manage their design artifacts (models, code, videos, photos, etc.), communities use open social platform that do not support a structured industrial processes, such as configuration management, traceability, change management, or validation and verification. Consequently, to collaboratively develop $\mathrm{OSH}$, companies and communities need new knowledge capture and reuse technologies blending the openness and flexibility of open source community-based product development with the quality and traceability of technologies used in industry.

\section{Conclusions}

Design reuse, which is a hot research topic in industrial product design, is also a core activity in the development of community-based OSH. In this paper, we try to better understand how design reuse can facilitate the development of OSH in companycommunity collaboration. First, our analysis shows that companies and communities include actors - makers and design engineers - who have the engineering background require to collaborate. Second, companies and communities share common goal for design reuse including the minimization of costs and time, but makers have different aim, such as personal development, improvement and personalization of a working tool, collective challenge, or simply have fun. Third, both entities use ICT to support their collaborative design activities; communities prefer to use web-based technologies for their openness and flexibility whereas companies adopt heavy information systems because they can meet their needs. Future work will focus on the specification and development of new methods and tools that could guide and support designers of OSH in the reuse of existing designs among and across the communities. 


\section{References}

1. Achten, H.H.: Requirements for collaborative design in architecture (2002)

2. Aksulu, A., Wade, M.R.: A comprehensive review and synthesis of open source research. J. Assoc. Inf. Syst. 11(11), 6 (2010)

3. Balka, K.: Open Source Product Development: The Meaning and Relevance of Openness. Springer Science \& Business Media, Berlin (2011)

4. Bonvoisin, J., Boujut, J.F.: Open design platforms for open source product development: current state and requirements. In: DS 80-8 Proceedings of the 20th International Conference on Engineering Design: Innovation and Creativity, Milan, Italy, vol. 8, pp. 011-020 (2015)

5. Bonvoisin, J., Buchert, T., Preidel, M., Stark, R.G.: How participative is open source hardware? insights from online repository mining. Des. Sci. 4 (2018)

6. Brissaud, D., Garro, O.: Conception distribuée, émergence. In: Tollenaere, M. (ed.), Conception de Produits Mécaniques: Méthodes, Modèles et Outils, pp. 105-114 (1998)

7. Hisarciklilar, O., Boujut, J.F.: A speech act theory-based information model to support design communication through annotations. Comput. Ind. 60, 510-519 (2009)

8. Kleinsmann, M.S.: Understanding collaborative design (2006)

9. Levandowski, C., Bokinge, M., Malmqvist, J., Johannesson, H.: PLM as support for global design reuse-long term benefits and immediate drawbacks. In: IFIP International Conference on Product Lifecycle Management, pp. 488-500. Springer, Berlin (2012)

10. Levine, S.S., Prietula, M.J.: Open collaboration for innovation: principles and performance. Organ. Sci. 25(5), 1414-1433 (2014)

11. Matta, N., Ducellier, G.: How to learn from design project knowledge. Int. J. Knowl. Learn. 9(1-2), 164-177 (2014)

12. Meehan, J.S., Duffy, A.H., Whitfield, R.I.: Supporting 'Design for Re-use' with modular design. Concurr. Eng. 15(2), 141-155 (2007)

13. Pakkanen, J., Huhtala, P., Juuti, T., Lehtonen, T.: Achieving benefits with design reuse in manufacturing industry. Procedia CIRP 50, 8-13 (2016)

14. Rezgui, Y., Boddy, S., Wetherill, M., Cooper, G.: Past, present and future of information and knowledge sharing in the construction industry: towards semantic service-based e-construction? Comput. Aid. Des. 43(5), 502-515 (2011)

15. Sanghee, K., Bracewell Rob, H.: Improving design reuse using context. In: Guidelines for a NPD Processes, the $16^{\text {th }}$ international conference of design engineering, DS42_P-54 (2007)

16. Sivaloganathan, S., Shahin, T.M.M.: Design reuse: an overview. Proc. Inst. Mech. Eng. J. Eng. Manuf. 213, 641-654 (1999)

Open Access This chapter is licensed under the terms of the Creative Commons Attribution 4.0 International License (http://creativecommons.org/licenses/by/4.0/), which permits use, sharing, adaptation, distribution and reproduction in any medium or format, as long as you give appropriate credit to the original author(s) and the source, provide a link to the Creative Commons license and indicate if changes were made.

The images or other third party material in this chapter are included in the chapter's Creative Commons license, unless indicated otherwise in a credit line to the material. If material is not included in the chapter's Creative Commons license and your intended use is not permitted by statutory regulation or exceeds the permitted use, you will need to obtain permission directly from the copyright holder.

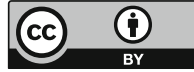

